ISSN: 2277-3754

ISO 9001:2008 Certified

International Journal of Engineering and Innovative Technology (IJEIT)

Volume 10, Issue 2, August 2020

\title{
Assessment of Day Care ability required in Yamaguchi area
}

\author{
Sachiko Mishima, Mahito Nakazono, Syohken Koh, Sachiko Yamamoto \\ Graduate Student of Sciences and Tec. for Innovation, Yamaguchi University, Japan
}

Abstract: As a result of maturing progress, older individuals with serious extent of care are expanding, and numerous old individuals are sitting tight for entering a nursing home. A day care office has a huge job, since standing by older individuals utilize a day care office until entering a nursing home. Then again, numerous day care offices are set up in urban territory, so there is the dissimilarity among urban and rocky region. This paper researches foundation of day care offices quantitatively by overview on the quantity of care-need certificated people and a satisfaction rate in Yamaguchi prefecture, where maturing is quickly cutting-edge and it is assessed to expand the interest of a day care office. The quantity of the consideration need certificated people of Yamaguchi prefecture has been determined. The assessment exactness is over 0.9, so boundary esteem is viable for assessing the quantity of the consideration need certificated individual of Yamaguchi prefecture. The office request of urban regions was higher than bumpy zones in 2010, in light of the fact that the new passages of a day care office expanded in urban regions after 2000. Also, as a result of diminishing the quantity of the consideration need certificated people, the satisfaction pace of an office request in uneven regions was higher than urban zones in 2015. Likewise, there is the uniqueness among the regions exceptionally in hilly regions, so it is imperative to consider the technique for office foundation in the regions, where the satisfaction rate is low.

Keywords: insurance system, Day care Care-need certificated person.

\section{BACKGROUND}

Because of aging progress, aging rate of 2014 became $26 \%$ and elderly people with high degree of care has continued to increase. The elderly people can use the visiting type, type to go to a facility, short-stay type and housing type service after introducing the aged person welfare work, such as the nursing-care insurance system. A day care facility is the type to go to facility and has a large role that providing the place where the elderly people spend in the daytime.

In previous studies of the field of building and city planning, there are the accumulations of the study such as a grasp of the location actual, evaluation of the service level, consideration and suggestion of optimal location layout planning 1-3), and classifying the characteristics of the demand for the elderly 4). On the other hand, about the problems considering disparities of welfare services, there are the accumulations of the study such as the research pointing out uneven distribution and regional disparity of the facilities location 5-6).

\footnotetext{
Manuscript received: 25 July 2020

Manuscript received in revised form: 20 August 2020

Manuscript accepted: 07 September 2020

Manuscript Available online: 15 September 2020
}

But there are few studies of analysis of the time-series change of facilities supply based on each small area for 15 years since nursing-care insurance system was introduced, as a target for whole area of the local prefecture including the urban region and rural region where the depopulation and aging is remarkable.

\section{METHODS}

Firstly, the number of care-need certificated persons of Yamaguchi prefecture has been estimated in 2000-2040, using the parameter values of before 2005 and after 2009 . And the parameter value is calculated by survey on a ratio of the care-need certificated persons of all over Japan. The data used for analysis are compiled from All-Japan Federation of National Health Insurance Organizations: the number of care-need certificated persons by age group and a care-need level in all over japan (2001-2015), result of national census and vital statistics (2000-2014) and National Institute of Population and Social Security Research: future population estimates (2015-2040).

Secondly, the estimation accuracy of the care-need certificated persons in Yamaguchi prefecture is calculated. The data used for analysis is compiled from WAM NET: the number of care-need certificated persons (Welfare and Medical Service Agency) (2001-2014).

Thirdly, a fulfillment rate of the facility demand has been calculated for every municipalities division before merger in the Heisei era, in order to analyze the states of facility establishment in detail. The fulfillment rate is a ratio of the facility capacity for the number of the careneed certificated persons. The data used for analysis is compiled from WEB site: insurance information Service Guide of Yamaguchi Prefecture / Database of Service Establishment / Day Care Facility (Elderly Citizens' Welfare Division in Yamaguchi Prefecture) (1985-2014).

\section{RESULTS}

\section{A. The number of the care-need certificated persons}

Figure 1 shows the change of the care-need person's number by an age group and a care-need level in all over Japan. The care requiring state sections have been able to divide into three periods. The state section of requiring help had one level in 2000-2005 as to first period. The state section of requiring help had two levels, and a temporary care level was added in 2006-2008 as to second period. The temporary care level was deleted after 2009 as to third period. The number of the care-need certificated persons was increased from $2,700,000$ people in 2001 to $6,180,000$ people in 2015 . The number of the 
ISSN: 2277-3754

\section{ISO 9001:2008 Certified \\ International Journal of Engineering and Innovative Technology (IJEIT) \\ Volume 10, Issue 2, August 2020}

care-need persons was increased $2,700,000$ people in 2001 to 4,217,000 people in 2005 in first period, because nursing care insurance system was just introduced. The number of them in 2008 was 4,638,000 people and the increase rate was low in second period. The increase rate was 1.6 times in third period. Therefore, the number of the care-need certificated person is increasing now, because of increasing the elderly people and prolonged life.

\section{B. The estimation method of the number of the care- need certificated persons}

The number of the care-need certificated persons of 2000-2040 in Yamaguchi prefecture has been estimated using the number of them in all over Japan. The data used for estimation are the number of them in 2001-2005 and 2009-2015, because the care requiring state sections is divided into three periods. And the number of the careneed certificated persons has been estimated separately for before 2005 and after 2009. Firstly, the ratio of the care-need certificated person is calculated by an age of group and a care-need level. Figure 2 and 3 show the ratio of the care-need certificated person with care level 1 . Secondly, parameter values are calculated using the ratio of the care-need certificated person. In this paper, if the change of ratio of the care-need certificated person for 5 years is over 0.01, parameter value is calculated using a regression equation. And if it is under 0.01, parameter value is calculated using an average. The parameter value of after 2009 has been calculated in 2 types, because the ratio of the care-need person of some aged groups is close to 0.01 . Table 1,2 and 3 show the parameter value by an age group and a care-need level.

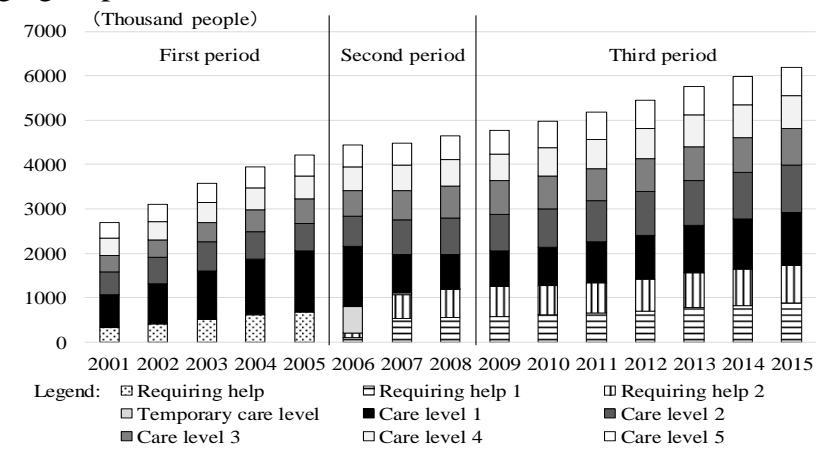

Fig. 1: Change of the care-need certificated person

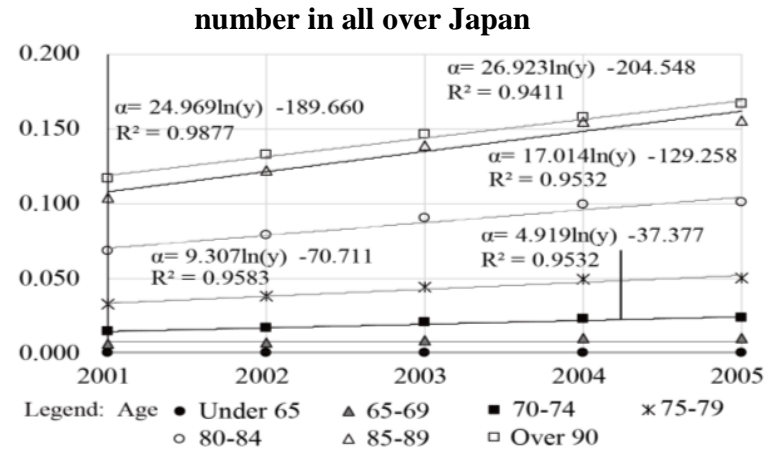

Fig. 2: The ratio of a care-need certificated person with care level 1 in 2001-2005

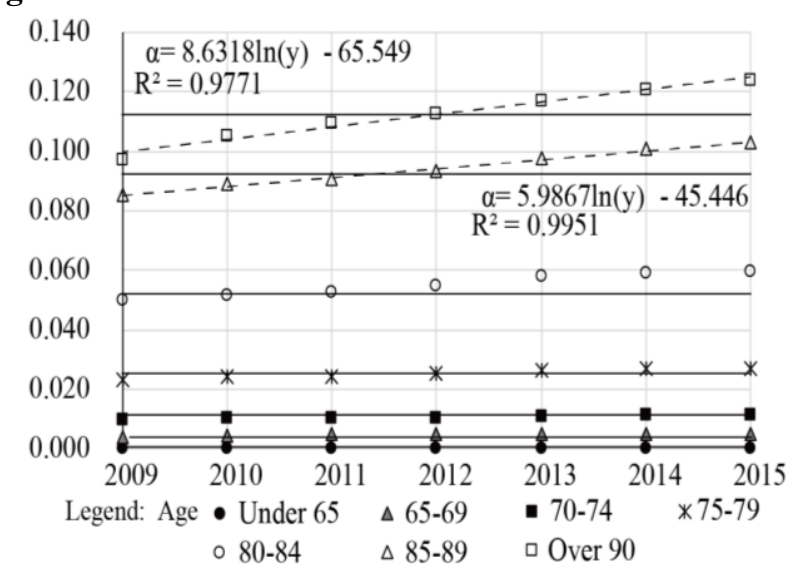

Fig. 3: The ratio of a care-need certificated person with care level 1 in 2009-2015

Thirdly, the number of the care-need certificated persons is estimated by based on the parameter value. The number of the care-need certificated persons by a careneed level is given by the following equation,

$\mathrm{Pj}=\alpha \mathrm{ij} \times \mathrm{Ai}$

Where $\mathrm{Pj}$ is the number of the care-need certificated persons by a care-need level, $\alpha \mathrm{ij}$ is the parameter value by an age group and a care-need level and $\mathrm{Ai}$ is the population by an age group.

Table 1: The parameter value by an age group and a care-need level before 2005

\begin{tabular}{c|c|c|r|r|r|r}
\hline Age & Requiring help & Care level 1 & Care level 2 & Care level 3 & Care level 4 & Care level 5 \\
\hline-65 & 0.00008 & 0.00039 & 0.00030 & 0.00019 & 0.00016 & 0.00019 \\
\hline $65-69$ & 0.00363 & 0.00840 & 0.00519 & 0.00356 & 0.00315 & 0.00329 \\
\hline $70-74$ & $\begin{array}{l}3.523 \times \ln (\mathrm{y})- \\
26.776\end{array}$ & $\begin{array}{l}4.919 \times \ln (\mathrm{y})- \\
37.377\end{array}$ & 0.01056 & 0.00739 & 0.00671 & 0.00680 \\
\hline $75-79$ & $\begin{array}{l}7.424 \times \ln (\mathrm{y})- \\
54.153\end{array}$ & $\begin{array}{l}9.307 \times \ln (\mathrm{y})- \\
70.711\end{array}$ & 0.02052 & 0.01466 & 0.01350 & 0.01329 \\
\hline $80-84$ & $\begin{array}{l}12.462 \times \ln (\mathrm{y})- \\
94.695\end{array}$ & $\begin{array}{l}17.014 \times \ln (\mathrm{y})- \\
129.258\end{array}$ & 0.04171 & 0.03050 & 0.02877 & 0.02747 \\
\hline $85-89$ & $\begin{array}{l}13.754 \times \ln (\mathrm{y})- \\
104.505\end{array}$ & $\begin{array}{l}26.923 \times \ln (\mathrm{y})- \\
204.548\end{array}$ & 0.07576 & 0.05908 & 0.05850 & 0.05377 \\
\hline $90-$ & $\begin{array}{l}7.330 \times \ln (\mathrm{y})- \\
55.685\end{array}$ & $\begin{array}{l}24.969 \times \ln (\mathrm{y})- \\
189.660\end{array}$ & 0.11014 & 0.10030 & 0.11720 & 0.10760 \\
\hline
\end{tabular}

Legend) y : Year

Table 2: The parameter value by an age group and a care-need level after 2009 type 1

\begin{tabular}{c|c|c|c|c|c|c|c}
\hline Age & Requiring & Requiring & Care level & Care level & Care level & Care level & Care level \\
& help 1 & help 2 & 1 & 2 & 3 & 4 & 5 \\
\hline-65 & 0.00015 & 0.00026 & 0.00030 & 0.00041 & 0.00028 & 0.00022 & 0.00025 \\
\hline $65-69$ & 0.00370 & 0.00424 & 0.00481 & 0.00538 & 0.00378 & 0.00310 & 0.00305 \\
\hline $70-74$ & 0.00955 & 0.00943 & 0.01071 & 0.01087 & 0.00774 & 0.00645 & 0.00603 \\
\hline $75-79$ & 0.02370 & 0.02163 & 0.02534 & 0.02273 & 0.01648 & 0.01406 & 0.01272 \\
\hline $80-84$ & 0.04732 & 0.04384 & 0.05502 & 0.04670 & 0.03451 & 0.02970 & 0.02613 \\
\hline $85-89$ & 0.06164 & 0.06507 & 0.09426 & 0.08572 & 0.06747 & 0.05949 & 0.05116 \\
\hline $90-$ & 0.04417 & 0.05975 & 0.11229 & 0.13229 & 0.12649 & 0.13211 & 0.11405 \\
\hline
\end{tabular}


ISSN: 2277-3754

ISO 9001:2008 Certified

International Journal of Engineering and Innovative Technology (IJEIT)

Volume 10, Issue 2, August 2020

Table 3: The parameter value by an age group and a care-need level after 2009 type 2

\begin{tabular}{c|c|c|c|c|c|c|c}
\hline Age & $\begin{array}{c}\text { Requiring } \\
\text { help 1 }\end{array}$ & $\begin{array}{c}\text { Requiring } \\
\text { help 2 }\end{array}$ & $\begin{array}{c}\text { Care level } \\
1\end{array}$ & $\begin{array}{c}\text { Care level } \\
2\end{array}$ & $\begin{array}{c}\text { Care level } \\
3\end{array}$ & Care level & Care level \\
4 & 5 \\
\hline-65 & 0.00008 & 0.00026 & 0.00039 & 0.00041 & 0.00028 & 0.00022 & 0.00025 \\
\hline $65-69$ & 0.00363 & 0.00424 & 0.00840 & 0.00538 & 0.00378 & 0.00310 & 0.00305 \\
\hline $70-74$ & 0.00955 & 0.00943 & 0.01071 & 0.01087 & 0.00774 & 0.00645 & 0.00603 \\
\hline $75-79$ & 0.02370 & 0.02163 & 0.02534 & 0.02273 & 0.01648 & 0.01406 & 0.01272 \\
\hline $80-84$ & $\begin{array}{l}3.985 \times \ln (\mathrm{y})- \\
30.266\end{array}$ & 0.04384 & 0.05502 & 0.04670 & 0.03451 & 0.02970 & 0.02613 \\
\hline $85-89$ & $\begin{array}{l}3.778 \times \ln (\mathrm{y})- \\
28.688\end{array}$ & 0.06507 & $5.987 \times \ln (\mathrm{y})-$ & 0.08572 & 0.06747 & 0.05949 & 0.05116 \\
\hline $90-$ & $\begin{array}{l}5.019 \times \ln (\mathrm{y})- \\
38.115\end{array}$ & 0.05975 & $8.632 \times \ln (\mathrm{y})-$ & 0.13229 & 0.12649 & 0.13211 & 0.11405 \\
\hline 65.549 & & & & & \\
\hline
\end{tabular}

Legend) $\mathrm{y}$ : Year

and the number of the care-need certificated persons is given by the following equation,

$$
\mathrm{P}(z) \quad \sum_{n=1}^{7}(\mathrm{Pj})
$$

Where $\mathrm{P}$ is the number of the care-need certificated persons.

The number of the care-need certificated persons of all over Japan has been calculated using the above equations and compared with actual values. The estimation accuracy is over 0.95 in almost years as to 2001-2005, but the estimation accuracy of 2001 is 0.93 and a little low. However, the estimation accuracy is over 0.9 in all years, so parameter value is effective for estimating the number of the care-need certificated persons. The estimation accuracy is over 0.95 in all years in case of using an average as to 2009-2015. and the estimation accuracy is over 0.99 in all years in case of using a regression equation. So, the estimation accuracy using a regression equation is higher than the estimation accuracy using an average. The estimation accuracy is over 0.9 in case of everything, so parameter value is effective for estimating the number of the care-need.

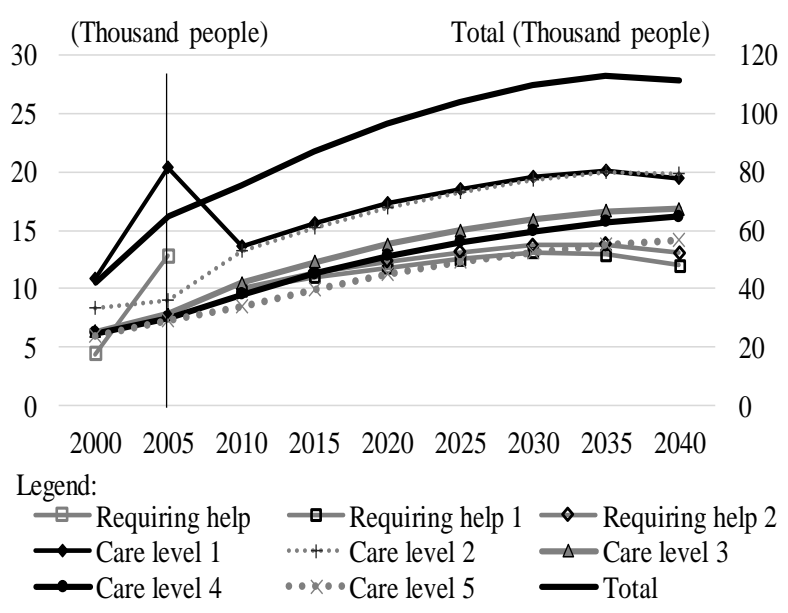

Fig. 4 The number of care-need certificated persons of Yamaguchi prefecture type 1

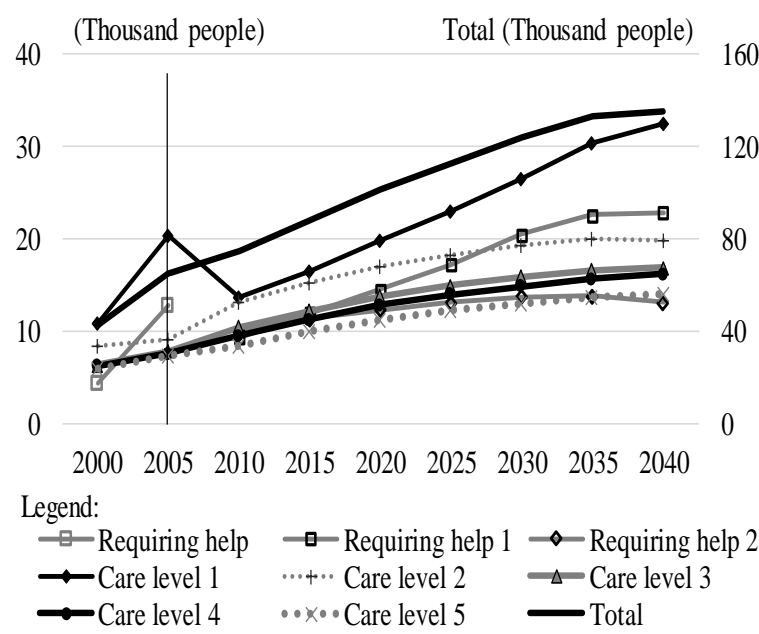

Fig. 5 The number of care-need certificated persons of Yamaguchi prefecture type 2 certificated person.

C. The estimation of the number of the care-need certificated persons of Yamaguchi prefecture

The number of the care-need certificated persons of Yamaguchi prefecture has been calculated. Figure 4 and 5 show the results. The increasing rate of the care-need certificated persons between 2000 and 2040 is about 3 times. And increasing rate between 2000 and 2005 is high especially. However, it has turned constant after 2035. According to a care level, increasing rates of them with care level 3 and 4 are about 2.6 and high.

The estimation results have been compared with actual values. The estimation accuracy is over 0.9 in all years as to 2001-2005, but the estimation accuracy of 2002-2004 is a little low. The estimation accuracy is over 0.95 in all years in case of using an average as to 2009-2015. And the estimation accuracy is over 0.98 in except for 2012 in case of using a regression equation.

Therefore, parameter value is also effective for estimating the number of the care-need certificated person of Yamaguchi prefecture, because the estimation accuracy is over 0.9 in all years. However, the parameter value of 2040 using a regression equation is twice the parameter value using an average, and $90 \%$ of the people aged over 90 are estimated to be care-need certificated persons. So, the parameter value using an average is used in this paper.

\section{The fulfillment rate of a day care facility demand in Yamaguchi prefecture}

The fulfillment rate of a day care facility demand in Yamaguchi prefecture is calculated by each selfgovernment body in 2000, because the facility demand is clarified in detail. The fulfillment rate is capacity of a day care facility to the number of the care-need certificated persons, and is effective for comparing the facility establishment conditions among the local governments. And the fulfillment rate of a day care facility is given by the following equation,

$$
\mathrm{F}=\mathrm{Cm} / \mathrm{Pm}
$$


ISSN: 2277-3754

ISO 9001:2008 Certified

International Journal of Engineering and Innovative Technology (IJEIT)

Volume 10, Issue 2, August 2020

Where $\mathrm{F}$ is the fulfillment rate of a day care facility, $\mathrm{Cm}$ is the facility capacity by the local government and $\mathrm{Pm}$ is the number of care-need certificated persons by the local government.

In 1990s, a day care facility with a special nursing home was established in each local government by introducing gold plan, so the facility capacity was same level in both of urban and mountainous areas in 2000. The facility capacity increased about three times in 2005 in urban area, because the facility supply rapidly progressed after 2000. On the other hand, the facility capacity increased only 1.5 times between 2000 and 2005 in mountainous area. After that, the facility supply progressed in both areas, so facility capacity increased to 11,352 people in urban area and to 3,532 people in mountainous area in 2015.

The number of the local governments where the fulfillment rate is between 0.15 and 0.19 is 14 and the most in mountainous area. And the number of the local governments where it is between 0.05 and 0.09 is 12 and the second most. However, there are the local governments where it is 0.04 or less and 0.25 or more, so there is the disparity among mountainous area. The fulfillment rate tends to be high in the area where the number of the care-need certificated persons is small in the northwestern part of the prefecture.

As mentioned above, the number of the care-need certificated persons of Yamaguchi prefecture has been calculated, and good results have been obtained. It is possible to analyze the states of facility establishment in detail by calculation of the fulfillment rate. And it is clarified that the fulfillment rate of mountainous areas was high in 2015, because the care-need certificated persons decreased. In addition, there is the disparity among the municipalities specially in mountainous areas, so it is important to consider the method of facility establishment in the municipalities, where the fulfillment rate is low.

\section{REFERENCES}

[1] Ogawa, H.,"A study on the establishment of local "Dayservice" centers for the elderly", Architectural Institute of Japan, 478, 1995, 89-98.

[2] Nakazono, M,"Supply and management from of regional welfare homes reused the existent Facilities by private associations", Architectural Institute of Japan, 624, 2008, 407-414.

[3] Kondo, M. and Takahashi, K.,"Evaluation of convenience and allocation planning of welfare facilities for elderly people", Architectural Institute of Japan, 37, 2002, 769774.

[4] Mishima, S.,"The change of day service sufficiency after the introduction of health care insurance system", Architectural Institute of Japan, 18 (40), 2012, 1025-1028.

[5] Miyazawa, H.,"Uneven nursing care service opportunity and the behavior of service providers under the long-term care insurance system, Architectural Institute of Japan, 76, 2003,59-80. 